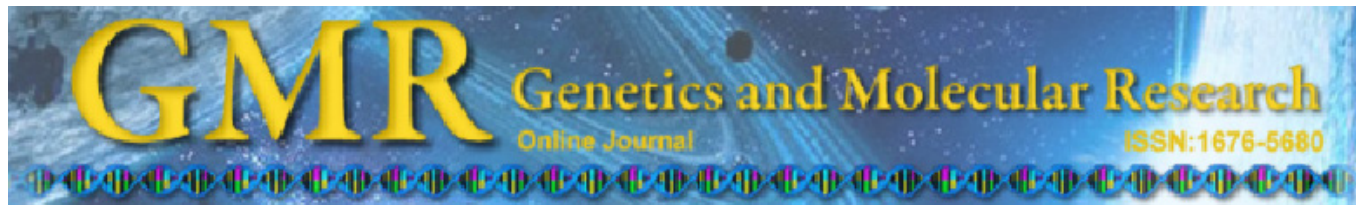

\title{
In vitro induction of tetraploid garlic with trifluralin
}

\author{
Z.-H. Cheng' ${ }^{1}$, X.-J. Zhou ${ }^{1}$, M.A. Khan ${ }^{1,2}$, L. Su${ }^{1}$ and H.-W. Meng ${ }^{1}$ \\ ${ }^{1}$ College of Horticulture, Northwest A \& F University, Yangling, \\ Shaanxi, China \\ ${ }^{2}$ PMAS-Arid Agriculture University, Rawalpindi, Pakistan
}

Corresponding author: Z.-H. Cheng

E-mail: chengzh@nwsuaf.edu.cn

Genet. Mol. Res. 11 (3): 2620-2628 (2012)

Received November 29, 2011

Accepted May 9, 2012

Published July 10, 2012

DOI http://dx.doi.org/10.4238/2012.July.10.13

\begin{abstract}
Garlic (Allium sativum) is propagated asexually. Since sexual cross breeding is almost impossible, means for effective breeding are not currently available and the available production cultivars are seriously aged and degenerated. A possible alternative for breeding is chemical induction. Trifluralin, a type of herbicide, has been reported to provoke chromosome doubling. However, this chemical had not been tested on garlic. We tested various trifluralin concentrations and treatment durations for efficiency in the induction of tetraploid garlic. A clove base of garlic with a stem cv. Gailiang was used as the ex-plant to induce calluses on Murashige and Skoog (MS) medium; the calluses were then inoculated onto MS medium containing different levels of trifluralin and cultured to induce chromosome number variation in vitro. Garlic calluses were effectively induced via the ex-plant and both shoots and roots differentiated well on MS medium containing 6-benzylaminopurine at $3.0 \mathrm{mg} / \mathrm{L}$ and indole-3-acetic acid at $0.1 \mathrm{mg} / \mathrm{L}$. However, increases in trifluralin concentration and treatment duration reduced the survival rate and differentiation rate of calluses. Garlic callus cultured for 15 days on medium containing $100 \mu \mathrm{M}$ trifluralin gave the highest rate of chromosome doubling. Through observation of chromosome number in the root apical cells and the morphology
\end{abstract}


of guard cells on the leaf epidermis of the regenerated plantlets, it was clear that chromosome number variation was induced and tetraploids were produced in vitro by trifluralin treatment.

Key words: Trifluralin; Tetraploid; Chemical induction of mutation; Garlic

\section{INTRODUCTION}

Garlic (Allium sativum L.), a widely used Allium crop worldwide, is often utilized as a popular condiment, flavoring agent and even the raw material of cosmetics, while the green garlic and the tender scape are consumed as green vegetables in China and some other Asian countries. It also has a wide range of medical uses because of its unique antibacterial and fungicidal properties (Afzal et al., 2000; Harris et al., 2001; Mousumi and Prabir, 2003; Khan et al., 2011). Garlic is a diploid species $(2 n=2 x=16)$ cultivated since 3000 years B.C. in Egypt. However, it is asexually propagated from cloves because of the sterile flowers, which are totally or partly replaced by bulbils (McCollum, 1987). Some attempts in garlic breeding have been reported (Guo and Xian, 2011), such as flower developing research (Kamenetsky and Rabinowitch, 2001), collection and induction of fertile garlic germplasms (Simon and Jenderekm, 2003), the production of transgenic garlic plants by organogenesis (Myers and Simon, 1998) or embryoenesis (Al-Zahim et al., 1999), mutant garlic lines selection by using crude pathogen filtrate (Zhang et al., 2012) and crossing garlic with onion (Yamashita et al., 2002) and leek (Yanagino et al., 2003). However, up to now, no surmounting breeding method has been established.

The induction of polyploidy is an efficient way to enhance the selective breeding of plants, which may show special superiority to sterile plants such as garlic, by improving morphology, disease resistance, adaptability to environmental stress and yield or quality. Many factors affect the induction of plant polyploidy, where the chromosome doubling agent and type of in vitro explants are thought to be the most important. The chromosome doubling agent should be not only efficient but also of low toxicity, and the explant should be reliable in propagation. In the production of crop polyploids, besides colchicine, other microtubule depolymerizing compounds, such as oryzalin, trifluralin and amiprophos-methyl (APM) at various concentrations and for various treatment durations have been tested (Wang and Wang, 2000; Qin et al., 2006; Stanys et al., 2006). A few efforts have also been directed at garlic polyploidy induction (Zhang and Li, 2006b; Xie and Deng, 2009). However, nowadays, colchicine is gradually substituted by other antimitotic agents due to its toxicity to humans by binding specifically to animal tubulin dimers. It was reported that antimicrotubule herbicides such as trifluralin are more specific for plant tubulin and mitosis in vitro compared to colchicine, and that these chemicals are at least as efficient as colchicine in chromosome doubling, but were less phytotoxic (Mu and Cao, 1999; Khosravi et al., 2008). However, for herbicides, the concentration is the key issue in their application. There have been reports on garlic chromosome doubling by pendimethalin (Zhou et al., 2009) and tetraploid melon mutation induction by trifluralin (Wei and Jiang, 2008; Yan et al., 2008), but to our knowledge, there has been no report on tetraploid garlic induction using trifluralin. As for explants in garlic, the immature umbels, bulblets, root fragments or root tips have been tested (Muhammad et al., 1997; Ayabe 
and Sumi, 1998; Robledo-Paz et al., 2000; Long et al., 2008), while the stem disc or clove base were thought to be more effective in callus or adventitious bud induction (Zhang and Cheng, 2003; Zhang and Li, 2006a).

In this study, the effect of concentration of trifluralin in MS medium on induction of tetraploid garlic was determined, and the ploidy of the induced plantlets and their morphology were examined, which may set an example and provide the foundation for further polyploid breeding in garlic.

\section{MATERIAL AND METHODS}

\section{Plant material}

Freshly harvested garlic bulbs cv. Gailiang were cured in the field, naturally air-dried for 30 days and then placed at a low temperature of $6^{\circ}-8^{\circ} \mathrm{C}$ to break dormancy. The cloves with no dormancy were rinsed with running water for 30-60 min after the skin and the brown base heel were removed, and then surface-sterilized by immersing in $70 \%(\mathrm{v} / \mathrm{v})$ ethanol for $30-60$ $\mathrm{s}$, soaked in $0.1 \%$ mercuric chloride solution for $20 \mathrm{~min}$, and at last rinsed with sterile distilled water three times. Afterwards, the clove was cut longitudinally with the top part removed and the lower part about $0.3 \sim 0.4 \mathrm{~cm}$ thick with the basal plate was sliced vertically into quarters, which were used as the initial explants.

\section{Callus induction and propagation}

Four explants were inoculated in each $100-\mathrm{mL}$ conical flask containing $40 \mathrm{~mL}$ Murashige and Skoog (MS) basal solid medium supplemented with $2 \mathrm{mg} / \mathrm{L}$ 2,4-dichlorophenoxyacetic acid (2,4-D) and $1 \mathrm{mg} / \mathrm{L}$ 6-benzyladenine (6-BA) and cultured under conditions of $25^{\circ} \pm 1{ }^{\circ} \mathrm{C}, 16$-h photoperiod and fluorescent light intensity of approximately $2000 \mathrm{~lx}$ for callus induction. The calluses growing well on explants after 30 days of culture were transferred and subcultured on MS medium supplemented with $2 \mathrm{mg} / \mathrm{L}$ $\alpha$-naphthalene acetic acid (NAA) and $1 \mathrm{mg} / \mathrm{L} 6$-BA for propagation. The $\mathrm{pH}$ of the culture medium was adjusted to 5.8 with $\mathrm{HCl}$ or $\mathrm{NaOH}$ before autoclaving at $121^{\circ} \mathrm{C}$ for $20 \mathrm{~min}$.

\section{Effects of growth regulators on shoot and root differentiation from calluses}

The calluses were subcultured once and inoculated on MS basal medium supplemented with different concentrations of 6-BA, 2,4-D and NAA (Table 1) and then cultured under the conditions noted above. There were three replications and 80 callus blocks for each treatment with 4 callus blocks inoculated in each conical flask. The results of shoot and root regeneration were recorded 8 weeks after culture.

\section{Induction of tetraploid with trifluralin in vitro}

Calluses were subcultured once and inoculated on solid MS medium (containing 0.05 $\mathrm{mg} / \mathrm{L} 2,4-\mathrm{D}$ and $1 \mathrm{mg} / \mathrm{L}$ 6-BA) with different concentrations $(0,50,100$, or $200 \mu \mathrm{M})$ of filtersterilized trifluralin and cultured for 5, 10 or 15 days. The calluses were then transferred to 
the same medium but without trifluralin for propagation. There were three replications and 80 callus blocks for each treatment with 4 callus blocks inoculated in each conical flask. After 3 weeks of culture, the callus survival rate was recorded and the surviving calluses were transferred to the differentiation medium (solid 1/2 MS medium supplemented with $3 \mathrm{mg} / \mathrm{L}$ 6-BA and $0.1 \mathrm{mg} / \mathrm{L}$ indole-3-acetic acid (IAA)) and cultured for 4 weeks to induce roots and shoots. The regenerated plantlets were removed from the culture medium, rinsed with tap water to remove the agar on roots, transplanted in pots filled with soil, and manure and acclimatized under greenhouse conditions. The chromosome number and stomatal morphology of the surviving plantlets were examined later.

\section{Chromosome number}

About $0.5 \mathrm{~cm}$ of the root tips of the plantlet were excised and placed in Carnoy's fixative (3:1 ethanol and glacial acetic acid) and stored at $3^{\circ}-5^{\circ} \mathrm{C}$ for $12 \mathrm{~h}$, rinsed with $95 \%$ $(\mathrm{w} / \mathrm{v}), 70 \%(\mathrm{w} / \mathrm{v})$ alcohol and distilled water three times, respectively, and then macerated for $15 \mathrm{~min}$ with $0.2 \mathrm{M} \mathrm{HCl}$ at $60^{\circ} \mathrm{C}$. After being soaked in distilled water for $30 \mathrm{~min}$, the fixed root tips were stained with improved carbol fuchsin $(1.8 \mathrm{~g}$ sorbitol dissolved in 10 $\mathrm{mL}$ carbol fuchsin, then mixed with $90 \mathrm{~mL} \mathrm{45 \%} \mathrm{(v/v)} \mathrm{acetic} \mathrm{acid)} \mathrm{for} \mathrm{microscopic} \mathrm{obser-}$ vation (Pang and Huang, 2003). A photomicroscope (Olympus BH-2, Japan) was used for chromosome observation. The chromosome count for each plantlet was repeated at least three times.

\section{Stomatal morphology}

For observation of stomatal morphology, collodion was smeared on the surface of leaf epidermis over an area of about $0.1 \mathrm{~cm}^{2}$. After the glue dried, the collodion impression was removed and observed under the microscope. Two leaves from each plantlet were sampled and 20 stomata were observed for each leaf.

\section{RESULTS}

\section{Effects of 6-BA, NAA and IAA on differentiation of garlic callus in vitro}

Shoot and root differentiation was very different on the medium with different levels of 6-BA, NAA and IAA (Table 1). The most root number (189 in total) but least shoot number (3 in total) was derived on the MS medium without any plant growth regulator. This result indicates that the differentiation of garlic root in vitro does not need any type of plant growth regulator but shoot differentiation needs the presence of growth regulators. 6-BA at $3.0 \mathrm{mg} / \mathrm{L}$ combined with IAA at $0.1 \mathrm{mg} / \mathrm{L}$ produced the best shoot induction of 94 shoots in total and 4.7 shoots per callus block. Root induction was also higher with 71 roots in total and 3.6 roots per callus block on the medium containing $3.0 \mathrm{mg} / \mathrm{L} 6-\mathrm{BA}$ and $0.1 \mathrm{mg} / \mathrm{L} \mathrm{IAA}$. This result indicates that the induction of garlic shoot needs the presence of a higher level of cytokine and lower level of auxin. Both shoot and root induction at a lower or medium level of 6-BA (0.5-2.0 $\mathrm{mg} / \mathrm{L})$ combined with NAA $(0.2-0.5 \mathrm{mg} / \mathrm{L})$ was not as high with only $0.4-2.3$ shoots per callus block and 1.8-2.8 roots per callus block. 


\begin{tabular}{|c|c|c|c|c|c|c|c|}
\hline \multicolumn{3}{|c|}{ Growth regulators $(\mathrm{mg} / \mathrm{L})$} & \multirow{2}{*}{$\begin{array}{l}\text { Number of callus } \\
\text { inoculated }\end{array}$} & \multirow{2}{*}{$\begin{array}{c}\text { Number of shoot } \\
\text { induced }\end{array}$} & \multirow{2}{*}{$\begin{array}{l}\text { Number of root } \\
\text { induced }\end{array}$} & \multirow{2}{*}{$\begin{array}{l}\text { Number of shoot } \\
\text { per callus }\end{array}$} & \multirow{2}{*}{$\begin{array}{l}\text { Number of root } \\
\text { per callus }\end{array}$} \\
\hline 6-BA & NAA & IAA & & & & & \\
\hline 0.5 & 0.2 & 0 & 21 & 25 & 38 & 1.2 & 1.8 \\
\hline 1.0 & 0.5 & 0 & 17 & 39 & 34 & 2.3 & 2.0 \\
\hline 2.0 & 0.3 & 0 & 20 & 7 & 55 & 0.4 & 2.8 \\
\hline 3.0 & 0 & 0.1 & 20 & 94 & 71 & 4.7 & 3.6 \\
\hline 0 & 0 & 0 & 18 & 3 & 189 & 0.2 & 10.5 \\
\hline
\end{tabular}

\section{Effect of trifluralin with different concentrations and treatment durations on survival and shoot differentiation of garlic callus}

The survival and shoot differentiation of garlic callus were strongly reduced by trifluralin treatment but depending on the concentration and treatment duration (Table 2).

\begin{tabular}{|c|c|c|c|c|c|c|}
\hline \multirow[t]{2}{*}{ Concentration of trifluralin $(\mathrm{mg} / \mathrm{L})$} & \multicolumn{3}{|c|}{$\begin{array}{l}\text { Survival rate }(\%) \text { of callus at } \\
\text { different treating duration }\end{array}$} & \multicolumn{3}{|c|}{$\begin{array}{l}\text { Shoot differentiating rate }(\%) \text { of callus } \\
\text { at different treating duration }\end{array}$} \\
\hline & 5 days & 10 days & 15 days & 5 days & 10 days & 15 days \\
\hline 0 & $92.5^{\mathrm{a}}$ & $86.1^{\mathrm{a}}$ & $98.0^{\mathrm{a}}$ & $62.3^{b}$ & $78.2^{\mathrm{a}}$ & $74.6^{\mathrm{a}}$ \\
\hline 50 & $69.2^{\mathrm{c}}$ & $56.3^{\mathrm{c}}$ & $36.7^{\mathrm{b}}$ & $77.2^{\mathrm{a}}$ & $63.5^{\mathrm{b}}$ & $36.7^{\mathrm{b}}$ \\
\hline 100 & $83.3^{\mathrm{b}}$ & $49.6^{\mathrm{d}}$ & $25.3^{\mathrm{c}}$ & $79.1^{\mathrm{a}}$ & $42.3^{\mathrm{c}}$ & $28.3^{\mathrm{c}}$ \\
\hline 200 & $90.1^{\mathrm{a}}$ & $60.4^{b}$ & $20.0^{\mathrm{d}}$ & $53.7^{\mathrm{c}}$ & $30.0^{\mathrm{d}}$ & $26.7^{\mathrm{c}}$ \\
\hline
\end{tabular}

Numbers followed by different superscript letters mean significant difference $(\mathrm{P}<0.05)$.

For short duration (5 days) of treatment, trifluralin caused a slight but significant decrease in garlic callus survival at a concentration of 50 and $100 \mu \mathrm{M}$. It was strange that the lower concentration showed less effect. However, with a treatment duration of 10 or 15 days, trifluralin produced a significant and increasing reduction in garlic callus survival with increasing concentration except for the treatment with $200 \mu \mathrm{M}$ for 10 days. It was very clear that the survival rate of garlic callus decreased sharply with increase in trifluralin treatment duration. The callus survival rate decreased to the lowest value of $20 \%$ when the concentration of trifluralin was increased to $200 \mu \mathrm{M}$ with the treatment duration increased to 15 days.

The inhibitory effect of trifluralin on shoot differentiation of garlic callus showed almost the same trend as the negative effect on survival. This means the shoot differentiation rate decreased significantly with increase in trifluralin concentration and increase in treatment duration. The shoot differentiation rate decreased to the lowest value of $26.7 \%$ when the concentration of trifluralin was increased to $200 \mu \mathrm{M}$ and the treatment duration increased to 15 days.

Calluses grown in medium containing trifluralin appeared compact, globular, and yellowish (Figure 1a). Many calluses turned brown and necrotic when transferred to trifluralin-free fresh medium. The surviving calluses were transferred to the shoot differentiation medium for further culture. Some the calluses formed buds and developed shoots with sheath and pseudostems (Figure 1b). After they were transferred to the rooting medium (MS + NAA $0.2 \mathrm{mg} / \mathrm{L}$ ) 
and cultured for 2 weeks, numerous adventitious roots formed rapidly on the base of shoots, with the root length up to $15 \mathrm{~cm}$ in the following weeks (Figure 1c). The regenerated plantlets with 3 leaves (Figure 1d) were then cultured at a lower temperature of $15^{\circ} \mathrm{C}$ for 15 days before transplanting to pot. The transplanted plantlets were acclimatized, and over $95 \%$ of the plantlets survived. After 2 weeks of growth the plantlets in pots (Figure 1e) appeared larger than the regenerated wild-type plantlets (regenerated from calluses not induced by trifluralin).
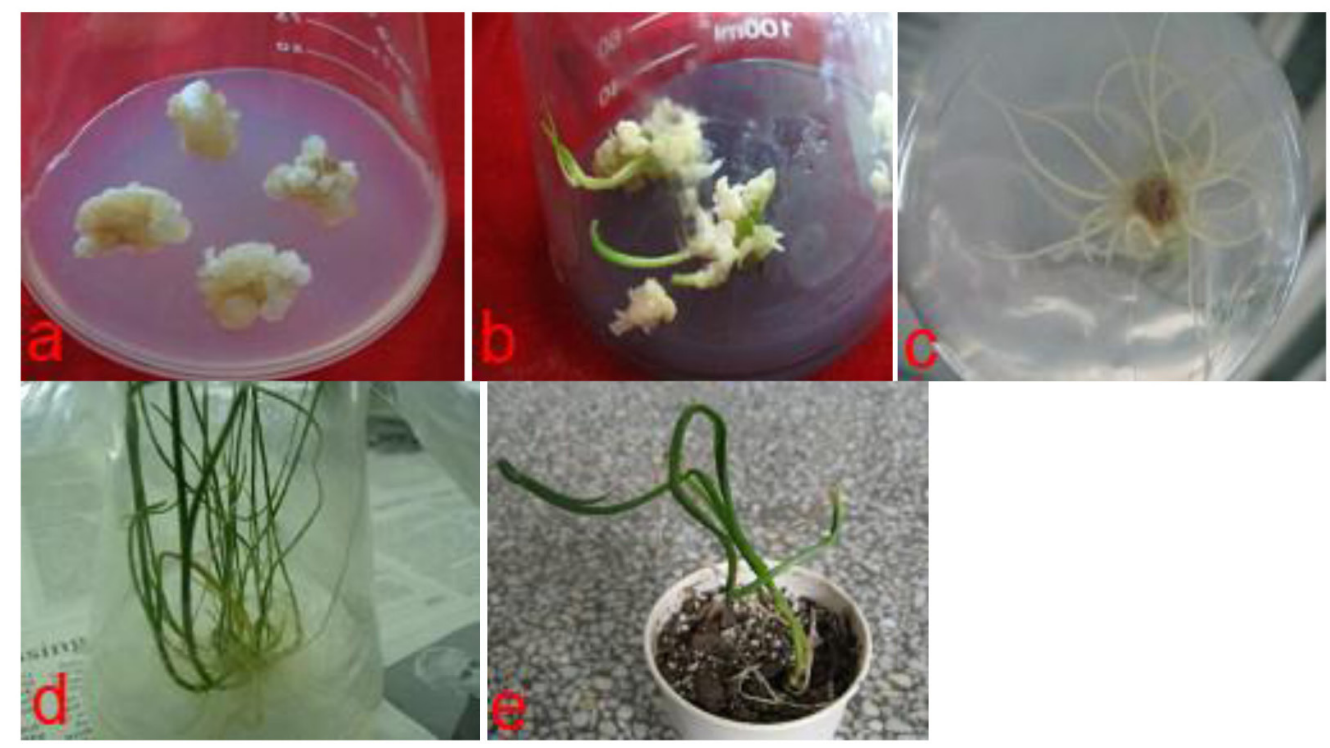

Figure 1. Induction of shoots, roots and plantlets from the callus grown on medium containing trifluralin. a. Calluses grown on medium with trifluralin. b. Shoots formed on trifluralin-induced calluses. c. Roots formed on trifluralin-induced calluses and shoots. d. Trifluralin-induced plantlets. e. Plantlets (tetraploid) transplanted in pot.

\section{Chromosome counts and examination of stomata of garlic after induced polyploidy}

The chromosome number and stomatal morphology of surviving trifluralin-induced plantlets were examined in this experiment.

The observation of root tip cell chromosome number showed that there were mixoploids, chimeras, diploids, and tetraploids in the plantlets induced by trifluralin depending on the concentration and treatment duration. No chromosome doubling occurred at all concentrations treated for 5 days and almost no tetraploid regenerated at a low concentration $(50 \mu \mathrm{M})$ of trifluralin. The tetraploid rates were 1.6 and $3.3 \%$, respectively for $100 \mu \mathrm{M}$ trifluralin for 10 and 15 days. There was no increase in tetraploid rate but decrease in diploid rate to $31 \%$ when triluralin concentration was increased to $200 \mu \mathrm{M}$ and the treatment duration increased to 15 days, while the mixoploid rate increased to the highest level $(16.7 \%)$ for this treatment (data not shown). Although the tetraploid induction rate in this research was low, comparatively speaking, the garlic calluses on MS medium containing $100 \mu \mathrm{M}$ trifluralin cultured for 15 days generated a higher tetraploid rate of $3.3 \%$. 
The results of chromosome counting confirmed that the chromosome number of the control plantlets (diploid) was $2 \mathrm{n}=2 \mathrm{x}=16$, while that of the autotetraploid plantlets was $2 \mathrm{n}$ $=4 \mathrm{x}=32$ (Figure 2 ).
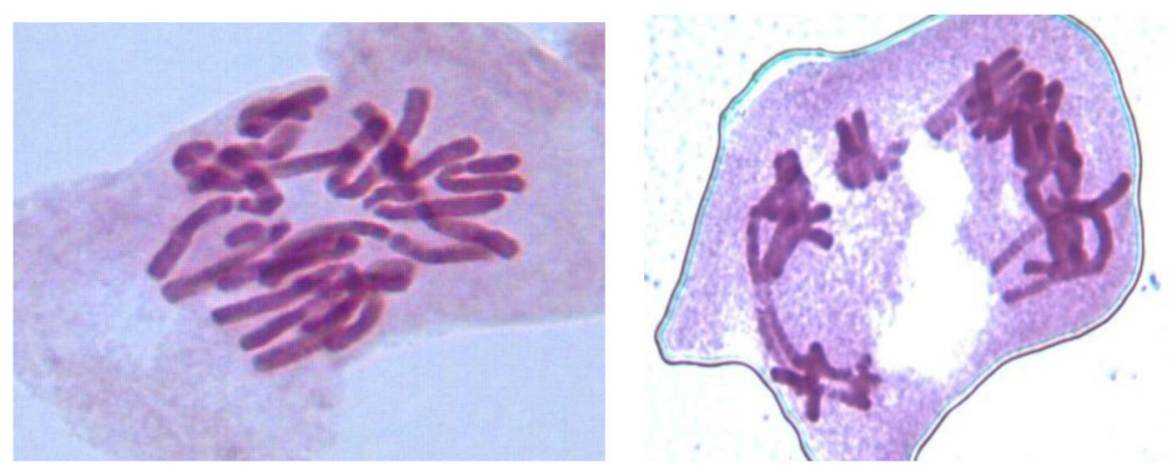

Figure 2. Chromosomes in root tip cell of diploid $(2 n=2 x=16)$ (left) and tetraploid $(2 n=4 x=32)$ (right) garlic plantlets.

The stomatal density (number in the same area) and guard cell size were observed, and stomatal density was higher and guard cells were small and thin in the diploid plantlets (Figure 3 , see left), while stomatal density was lower and guard cells larger and thick in the tetraploid plantlets (Figure 3, see right).
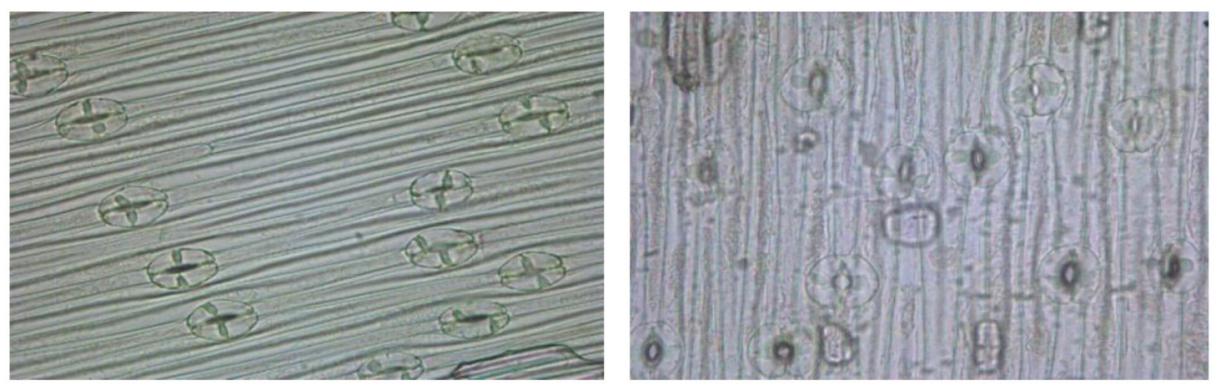

Figure 3. Stomata of diploid (left) plantlets and trifluralin-induced tetraploid (right) plantlets of garlic.

The plantlets showing variation in chromosome number and stomatal morphology also exhibited normal growth vigor. All these phenomena were consistent with the characteristics of polyploidy. Therefore, it is thought that tetraploid plantlets were induced by trifluralin in this study.

\section{DISCUSSION}

Polyploidy induction by antimitotic agents, such as colchicine, APM, oryzalin, and trifluralin by arresting mitosis at the anaphase stage, play an increasingly important role in 
crop breeding (Thao et al., 2003; Stanys et al., 2006). Although considerable progress has been made in the induction and production of Allium plants by antimitotic agents (Campion et al., 1995; Grzebelus and Adamus, 2004), there is no report on tetraploid garlic induction by trifluralin. It was reported that $1 \mu \mathrm{M}$ trifluralin generated more normal and fertile plants in embryogenic microspore cultures of Brassica napus compared to 25 or $50 \mu \mathrm{M}$ colchicine (Zhao and Simmonds, 1995) and that trifluralin showed a higher affinity to plant tubulin than did colchicine (Zhang and Zhang, 2003). Compared to the highest rate of tetraploid induced by trifluralin using root tips from germinated seeds, which was $32.2 \%$ in melon (Wei and Jiang, 2008), the garlic tetraploid inducing rate in vitro in this research was much lower (only $3.3 \%$ ). This may be related to the species and explant material.

Trifluralin, as a kind of herbicide, may inhibit explant growth, callus induction and differentiation, and even cause callus browning or death. Therefore, the concentration and treatment duration are key factors for tetraploid induction. Previous studies showed that a high concentration of trifluralin combined with short-duration treatment or low concentration combined with a longer duration of treatment favored the successful induction of tetraploids in Beta vulgaris (Hansen et al., 2000). In this research, almost no tetraploid plantlets regenerated with the shortest treatment duration (5 days) and for all treatment durations at the lowest concentration $(50 \mu \mathrm{M})$ of trifluralin. The highest tetraploid rate of $3.3 \%$ was obtained with callus cultured on MS medium containing $100 \mu \mathrm{M}$ trifluralin for 15 days.

A higher concentration of trifluralin, especially for longer treatment durations showed more toxicity toward garlic callus resulting in a lower survival rate and differentiation rate, which is consistent with the study of Grzebelus and Adamus (2004) in genome doubling of onion.

Apart from the concentrations and treatment durations of trifluralin, other factors such as temperature, hormones and in vitro culture conditions may also affect the efficiency of tetraploid induction. As a multi-factor influenced process, polyploidy induction needs to be further investigated especially with regard to other factors to optimize the induction system and increase the tetraploid plant rate for in vitro induction of tetraploid garlic.

\section{ACKNOWLEDGMENTS}

Research supported by project of the State Commonwealth Industry (Agriculture) Scientific Research (\#200903018), China.

\section{REFERENCES}

Afzal M, Ali M, Thomson M and Armstrong D (2000). Garlic and its medicinal potential. Inflammopharmacology 8: 123-148.

Al-Zahim MA, Ford-Lloyd BV and Newbury HJ (1999). Detection of somaclonal variation in garlic (Allium sativum L.) using RAPD and cytological analysis. Plant Cell Rep. 18: 473-477.

Ayabe M and Sumi S (1998). Establishment of a novel tissue culture method, stem-disc culture, and its practical application to micropropagation of garlic (Allium sativum L.). Plant Cell Rep. 17: 773-779.

Campion B, Perri E, Azzimonti MT, Vicini E, et al. (1995). Spontaneous and induced chromosome doubling in gynogenic lines of onion (Allium cepa L.). Plant Breed. 114: 243-246.

Grzebelus E and Adamus A (2004). Effect of anti-mitotic agents on development and genome doubling of gynogenic onion (Allium cepa L.) embryos. Plant Sci. 167: 569-574.

Guo RF and Xian F (2011). Research advance of garlic breeding technology. J. Anhui Agric. Sci. 39: 2617-2619, 2890.

Hansen AL, Gertz A, Joersbo M and Andersen SB (2000). Chromosome doubling in vitro with amiprophos-methyl in Beta vulgaris ovule culture. Acta Agric. Scand. B Soil Plant Sci. 50: 89-95. 
Harris JC, Cottrell SL, Plummer S and Lloyd D (2001). Antimicrobial properties of Allium sativum (garlic). Appl. Microbiol. Biotechnol. 57: 282-286.

Kamenetsky R and Rabinowitch HD (2001). Floral development in bolting garlic. Sex. Plant Reprod. 13: 235-241.

Khan MA, Cheng ZH, Xiao XM, Khan AR, et al. (2011). Ultrastructural studies of the inhibition effect against Phytophthora capsici of root exudates collected from two garlic cultivars along with their qualitative analysis. Crop Protect. 30: 1149-1155.

Khosravi P, Kermani MJ, Nematzadeh GA, Bihamta MR, et al. (2008). Role of mitotic inhibitors and genotype on chromosome doubling of Rosa. Euphytica 160: 267-275.

Long YJ, Wu Z, Yang Y, Li CH, et al. (2008). Anatomy of organogenesis from garlic (Allium sativum L.) rachis in vitro culture. Acta Bot. Boreali-Occidentalia Sin. 28: 470-474.

McCollum GD (1987). Onion and Allies. In: Evolution of Crop Plants (Simmomds NW, ed.). Longman S \& T, London, 186-190.

Mousumi B and Prabir KS (2003). Inhibitory effect of garlic on bacterial pathogens from spices. World J. Microbiol. Biotechnol. 19: 565-569.

Mu XQ and Cao W (1999). Herbicide on the plant cell mitosis impact. Weed Sci. 1: 11-13.

Muhammad SH, Tomikichi W and Kazumi H (1997). High frequency shoot regeneration and plantlet formation from root tip of garlic. Plant Cell Tissue Organ Cult. 50: 83-89.

Myers JM and Simon PW (1998). Continuous callus production and regeneration of garlic (Allium sativum L.) using root segments from shoot tip-derived plantlets. Plant Cell Rep. 17: 726-730.

Pang RY and Huang ZY (2003). The way to improve the inducing polyploid in experiment. J. Yulin Teach. Coll. 87-88.

Qin SP, Chen YH, Lin XH, Zhou LY, et al. (2006). Effects of colchicine on mitosis and polyploid induction in rye. $J$. Nuclear Agr. Sci. 20: 321-323.

Robledo-Paz A, Villalobos-Arambula VM and Jofre-Garfias AE (2000). Efficient plant regeneration of garlic (Allium sativum L.) by root-tip culture. In Vitro Cell. Dev. Biol. Plant 36: 416-419.

Simon PW and Jenderekm M (2003). Flowering, seed production and the genesis of garlic breeding. Plant Breed. Rev. 32: 211-244.

Stanys V, Weckman A, Staniene G and Duchovskis P (2006). In vitro induction of polyploidy in Japanese quince (Chaenomeles japonica). Plant Cell Tissue Organ Cult. 84: 263-268.

Thao NTP, Ureshino K, Miyajima I, Ozaki Y, et al. (2003). Induction of tetraploids in ornamental Alocasia through colchicine and oryzalin treatments. Plant Cell Tissue Organ Cult. 72: 19-25.

Wang MQ and Wang XH (2000). A primary study on induction of grape polyploidy. Shandong Agr. Sci. 1: 19-20.

Wei YG and Jiang JF (2008). The preliminary explore on induction of tetraplodin muskmelon with trifluralin. Acta Agric. Boreali-Sin. 21: 73-76.

Xie XL and Deng ZF (2009). Analysis on the influences of colchicine on the growth of Allium sativum and its polyploid induction effect. J. Anhui Agric. Sci. 37: 4191-4194.

Yamashita K, Hisatune Y and Sakamoto T (2002). Chromosome and cytoplasm analyses of somatic hybrids between onion (Allium cepa L.) and garlic (A. sativum L.). Euphytica 125: 163-167.

Yan ZH, Liu WG, Zhao SJ and He N (2008). In vitro induction of tetraploid watermelon using dinitroaniline herbicide. Acta Hortic. Sin. 35: 1621-1626.

Yanagino T, Sugawara E and Watanabe M (2003). Production and characterization of an interspecific hybrid between leek and garlic. Theor. Appl. Genet. 107: 1-5.

Zhang ER and Cheng ZH (2003). Study on in vitro selection of salt-tolerant calluses of garlic. Acta Bot. BorealiOccidentalia Sin. 23: 1571-1576.

Zhang LQ, Cheng ZH, Khan MA and Zhou Yl (2012). In vitro selection of resistant mutant garlic lines by using crude pathogen culture filtrate of Sclerotium cepivorum. Aust. Plant Pathol. 41: 211-217.

Zhang QM and Zhang MF (2003). Progresses on polyploid induction of horticultural crops. Chin. J. Cell Biol. 223-228.

Zhang SZ and Li JR (2006a). Effect of plant growth regulators combination to the stem disc callus regeneration system of garlic (Allium sativum L.). Seed 6: 38-40.

Zhang SZ and Li JR (2006b). Study on colchicine-induced tetraploid in garlic (Allium sativum L.). J. Nuclear Agric. Sci. 20: 303-308.

Zhao J and Simmonds DH (1995). Application of trifluralin to embryogenic microspore cultures to generate doubles haploid plants in Brassica napus. Physiol. Plant 95: 304-309.

Zhou XJ, Cheng ZH and Meng HW (2009). Effects of pendimethalin on garlic chromosome doubling in vitro. Acta Bot. Boreali-Occidentalia Sin. 29: 2571-2575.Veliqui quaectio. Ro beatis rem solores sinciis soloreicid ut hillaciendae prore con culparu mquiandita acernam, ut ipsa nescipitatur sim landam labo. Ferae officatem facerempos quas erchill 